\begin{tabular}{|c|c|}
\hline Journal STAND: Sports and Development \\
unipa Sumalaya & $\mathrm{http} / /$ jurnal.unipasby.ac.id/index.php/stand/about/submissions \\
\hline
\end{tabular}

\title{
PENINGKATAN TEKNIK DASAR SMASH PERMAINAN BOLAVOLI MELALUI PENGGUNAAN MEDIA BOLA GANTUNG
}

\author{
Imam Almaturidi1 ${ }^{1}$, Andi Fepriyanto2 ${ }^{2}$, Mas'odi3 $^{3}$ \\ ${ }^{1}$ Program studi Pendidikan Jasmani Kesehatan dan Rekreasi, (STKIP PGRI) Sumenep \\ Email: imamalmaturudi02@gmail.com ${ }^{1}$ Email: andifepriyanto@stkippgrisumenep.ac.id ${ }^{2}$ \\ Email:masodi@stkippgrisumenep.ac.id ${ }^{3}$
}

\begin{tabular}{l}
\hline Artikel Info \\
\hline Koresponden penulis: \\
Imam Almaturidi \\
Email. \\
imamalmaturudi02@gmail.com \\
$\square$ Diterima 27 April 2020 \\
$\square$ Direview 19 Mei 2020 \\
$\square$ Disetujui 26 Mei 2020 \\
$\square$ Dipublikasi 27 Mei 2020 \\
\\
Kata Kunci: \\
Media pembelajaran, hasil belajar siswa, \\
Permainan bolavoli.
\end{tabular}

Media pembelajaran, hasil belajar siswa,
Permainan bolavoli.

$\overline{-20}$

\footnotetext{
Keywords:

Learning media, student learning outcomes, volleyball games.
}

\begin{abstract}
Abstrak
Tujuan dari penelitian ini adalah meningkatkan teknik dasar smash permainan bolavoli melalui penggunaan media bola Gantung. Penelitian ini dilakukan pada siswa kelas 7 H di MTsN 2 sumenep. Menggunakan metode penelitian tindakan kelas (PTK) dengan subjek pada penelitian ini adalah seluruh siswa 7H MTsN 2 Sumenep berjumlah 31 siswa. Hasil penelitian menunjukkan bahwa peningkatan teknik dasar smash bolavoli siswa pada siklus I dengan penggunaan media bola gantung diperoleh smash sikap permulaan 16 siswa, sikap awalan 15 siswa, sikap perkenaan dengan bola 19 siswa dan sikap mendarat 17 siswa. Sedangkan pada siklus II diketahui bahwa siswa benar sikap permulaan 25 siswa, sikap awalan 27 siswa, sikap perkenaan dengan bola 29 siswa dan sikap mendarat 29 siswa.sehingga dapat disimpulkan bahwa ada peningkatan teknik dasar smash bolavoli pada siswa siswa 7H MTsN 2 Sumenep melalui penggunaan media bola gantung.
\end{abstract}

\begin{abstract}
This study aims to improve the basic techniques of volleyball smash games through the use of Hanging Ball media. This research was conducted on $7 \mathrm{H}$ grade students at MTsN 2 Sumenep. Using the classroom action research (PTK) method with the subjects in this study were all 7 students of MTsN 2 Sumenep totaling 31 students. The results showed that the improvement of the basic techniques of volleyball smash for students in the first cycle with the use of hanging ball media obtained 16 students 'initial attitude smashes, 15 students' prefix attitudes, 19 students 'wear attitudes towards the ball and 17 students' landing attitudes. Whereas in the second cycle it is known that the students are correct at the beginning of 25 students, 27 students are prefixed, 29 students are on the ball and landing is 29 students. hanging ball
\end{abstract}




\begin{tabular}{|c|c|c|}
\hline Journal STAND: Sports and Development & http://jurnal.unipasby.ac.id/index.php/stand/about/submissions \\
unipa Sumalay & jurnal.stand@unipasby.ac.id
\end{tabular}

\section{PENDAHULUAN}

Pembelajaran bolavoli merupakan proses atau cara seseorang dalam belajar bermain bolavoli yang bertujuan memperluas wawasan serta peningkatan dan penerapan nilai-nilai pengetahuan dan kemampuan dalam bermain. Bolavoli merupakan suatu permainan beregu yang dimainkan oleh dua tim yang saling berhadapan dan masing-msing terdiri enam pemain (Redaksi, 2008 : 1) bahkan permainan ini lebih ditekankan lagi khususnya menguasai teknik-teknik dasarnya, penguasaan teknik dasar yang baik akan memudahkan seorang pemain dalam menjalankan strategi dan akan timbul rasa percaya diri yang tinggi serta selalu optimis dalam setiap pertandingan (Listiana, $2012: 2)$.

Teknik dasar yang paling penting yaitu smash, karena smash merupakan suatu pukulan yang kuat dimana tangan kontak dengan bola secara penuh pada bagian atas sehingga jalannya bola terjadi dengan kecepatan yang tinggi, apabila pukulan bola lebih tinggi berada diatas net, maka bola dapat dipukul tajam ke bawah (Kurniawan, 2012 : 120). Selain itu

Berdasarkan hasil studi pendahuluan dengan observasi dan wawancara di MTsN 2 Sumenep dengan guru pengajar dan siswa MTsN 2 Sumenep diketahui bahwa memiliki sarana dan prasarana olahraga yang cukup baik, khususnya untuk sarana permaianan bolavoli. Observasi yang dilakukan kepada siswa yang mengikuti pembelajaran bolavoli di MTsN 2
Sumenep, dimana $(60 \%)$ pada tahap tolakan siswa belum menguasai tekniknya, dan (40\%) siswa masih banyak mengalami kendala saat melakukan teknik melayang dan guru pengajar menyatakan bahwa siswa yang mengikuti pembelajaran bolavoli masih belum sepenuhnya menguasai teknik dasar bolavoli. Permasalahan yang muncul pada saat kegiatan pembelajaran bolavoli di MTsN 2 Sumenep adalah pada saat mempraktikkan smashpada tahap awalan, tolakan, melayang, dan mendarat. masih ada banyak siswa yang memiliki kemampuan smash kurang baik dan sebagian siswa lainnya memiliki kemapuan smash yang baik. Mengingat bahwa dalam pembelajaran bolavoli di MTsN 2 Sumenep hanya diberikan teknik dasar saja dan belum pernah menggunakan media bola gantung sehingga menyebabkan kurangnya keterampilan khususnya smashdalam bolavoli pada siswa di MTsN 2 Sumenep maka perlu ditelusuri faktor penyebabnya, apakah karna dipengaruhi oleh gerakan tangan dengan bola belum tepat atau disebabkan faktor gerakan lainnya. Kemudian Hasil wawancara peneliti pada siswa, Rata-rata siswa belum menguasai teknik dalam melakukan gerakan smash. Dalam hal ini proses pembelajaran bolavoli dalam meningkatkan hasil belajar smashdapat dilakukan dengan metode gerakan smash dengan bola gantung. Berdasarkan permasalahan yang ada maka peneliti melakukan penelitian tentang penerapan media bola gantung terhadap peningkatan hasil belajar

Volume 1 Nomor 1 Tahun 2020 | 44 


\section{Journal STAND: Sports and Development}

http://jurnal.unipasby.ac.id/index.php/stand/about/submissions jurnal.stand@unipasby.ac.id

smash dalam permainan bolavoli pada siswa kelas 7 H di MTsN 2 Sumenep.

\section{KAJIAN LITERATUR DAN PEGEMBANGAN HIPOTESIS (JIKA ADA)}

Belajar seringkali tidak disadari oleh kebanyakan manusia. Belajar merupakan pekerjaan biasa dilakukan oleh manusia pada umumnya ketika manusia ingin bisa melakukan sesuatu tertentu. Pada dasarnya merupakan suatu proses yang berakhir pada perubahan. Belajar tidak pernah memandang siapa pengajarnya, dimana tempatnya dan apa yang diajarkan. Tetapi dalam hal ini lebih menekankan pada hasil dari pembelajaran tersebut. Perubahan apa yang terjadi setelah melakukan pembelajaran. Seringkali kita mendengar kata "Belajar" bahkan tidak jarang pula menyebutkannya, tetapi kita belum mengetahui secara detail makna apa yang sebernanya makna yang terkandung dalam belajar itu (Fathurrohman, 2017: 1).

Suatu prinsip untuk memilih pendekatan pembelajaran ialah belajar melalui proses mengalami secara langsung untuk memperoleh hasil belajar yang bermakna. Proses tersebut dilaksanakan melalui interaksi antara siswa dengan lingkungannya (Suardi, 2018: 10). Bola gantung merupakan salah satu media yang dapat digunakan sebagai perantara untuk mentransfer dalam menyampaikan pesan dari pengirim ke penerima khususnya pada media mempraktekkan teknik smash pada bolavoli. Bola gantung yang dimaksud dalam pengertian ini adalah bola yang digantung dengan seutas tali yang diikat pada ujung tiang yang berporos pada pengikat tali, dengan menggunakan bolavoli pada ketinggian sesuai dengan jangkauan pemain. Latihan memukul bola gantung secara mekanik mampu mengembangkan kecepatan dan ketepatan memukul bola. Dengan awalan langkah serta ketepatan memukul bola yang dilakukan secara berulang-ulang dapat melatih respon memukul bola yang pas dan dapat melatih respon memukul bola yang pas dan dapat melatih agar mencapai raihkan bola yang tinggi serta lompatan yang tinggi pula (Erfian, $2013: 24$ ).

Bentuk latihan bola gantung dengan ketinggian semakin meningkat testi beridiri tegak dibawah bola, menggunkan awalan 1 langkah, 2 langkah, 3 langkah, 4 langkah. Selanjutnya menggunakan ancang-ancang (runup) kemudian melompat tangan kanan memukul bola yang digantung dengan sikap melayang di udara. Kemudian mendarat menggunakan kedua kaki dengan ketinggian semakin meningkat $185 \mathrm{~cm}, 190 \mathrm{~cm}, 195 \mathrm{~cm}$, $200 \mathrm{~cm}, 205 \mathrm{~cm}, 210 \mathrm{~cm}$ sampai $250 \mathrm{~cm}$. Adapun awalan memukul dimulai dari bawah bola, 1 langkah, 2 langkah, 3 langkah, 4 langkah (Erfian, 2013: 25). Ukuran panjang tali lurus penggantung bola $9 \mathrm{~cm}$, tinggi bola untuk putra $2.43 \mathrm{~cm}$ sedangkan putri $2,24 \mathrm{~cm}$. Tujuan dibuatnya media bola gantung ini yaitu mempermudah siswa/siswi dalam pemahaman permulaan teknik dasar smash dalam permainan bola voli. Keterangan: ukuran tinggi tiang atau bola gantung dari lantai dapat 


\begin{tabular}{|c|c|c|}
\hline Unipa Surabaya & $\begin{array}{c}\text { Journal STAND: Sports and Development } \\
\text { http://jurnal.unipasby.ac.id/index.php/stand/about/submissions } \\
\text { jurnal.stand@unipasby.ac.id }\end{array}$ & 0 \\
\hline
\end{tabular}

disesuaikan dengan kebutuhan pemakai. Biasanya pemula digunakan ukuran rendah (Zuhermandi, dkk, 2015: 24).

\section{METODE PENELITIAN}

Dalam memecahkan masalah sangat diperlukan suatu cara atau metode, karena metode merupakan faktor penting dalam menentukan keberhasilan dari suatu penelitian terhadap subjek yang akan diteliti. Dalam penelitian ini peneliti menggunakan metode penelitian tindakan kelas (PTK). Penelitian ini merencanakan penelitian dua siklus dan setiap siklus memiliki tindakan yang berbeda. Setiap proses penelitian merupakan tindak lanjut dari siklus penelitian sebelumnya. Penelitian tindakan ini dilakukan melalui putaran atau spiral yang disetiap siklusnya terdiri dari rencana, tindakan, observasi, refleksi.

Subjek yang digunakan pada penelitian ini adalah siswa 7 H MTsN 2 Sumenep yang berjumlah 31 siswa. Pengambilan data menyesuaikan dengan jam pelajaran yang sudah ada sehingga tidak merubah kegiatan siswa. Start dari jam 07:00 - 9:00 WIB sesuai jam pembelajaran.

Penelitian ini diawali dengan menemui siswa yang mengikuti pembelajaran bolavoli untuk meminta menjadi subyek, melakukan tindakansiklus 1 dan siklus 2 yang meliputi kegiatan pembelajaran teknik dasar smash bolavoli dengan menggunakan media bola gantung, dan peneliti melakukan pendampingan mulai tahap persiapan hingga pelaksanaan pembelajaran bolavoli.

Teknik analisis data yang digunakan dalam penelitian ini menggunakan teknik analisis data Kuantitatif, mengetahui temuan temuan yang ada, melalui observasi terhadap teknik dasar smash bolavoli pada siswa sebelum dan sesudah diberikan tindakan penggunaan media pembelajaran bola gantung dalam proses pembelajaran bolavoli.

\section{HASIL DAN PEMBAHASAN}

Pelakasanaan penelitian peningkatan teknik dasar smash dalam permainan bolavoli dengan menggunakan media bola gantung yang dilakukan pada siswa kelas $7 \mathrm{H}$ di MTsN 2 Sumenep pada siklus pertama atau pertemuan pertama yaitu siswa mempersiapkan diri dilapangan, siswa dibariskan, dan dibagi menjadi 3 baris, setelah itu dipimpin berdoa dan dilakukan absensi, Kemudian siswa diberikan penjelasan mengenai tujuan dan bentuk pembelajaran yang akan dilakukan, yaitu teknik dasar smash bolavoli dimana menjelaskan posisi dari sikap awalan, tolakan, melayang dan sikap akhir mendarat. Setelah dipahami dilakukan pemanasan stretching aktif dan kalestenik serta permainan kecil. Sebelum siswa melakukan praktek satu persatu teknik dasar smash bolavoli dengan media bola gantung siswa diberikan contoh rangkaian teknik dasar smash bolavoli mulai dari sikap persiapan, pelaksanaan dan sikap akhir dengan menggunakan bola gantung yang baik dan benar. 


\begin{tabular}{|c|c|c|}
\hline & Journal STAND: Sports and Development \\
unipa Sumalaya & http:/jurnal.unipasby.ac.id/index.php/stand/about/submissions \\
jurnal.stand@unipasby.ac.id
\end{tabular}

Siswa melakukan pengulangan teknik dasar smash bolavoli secara bergantian dan berurutan dengan media bola yang digantung dengan ketinggian menyesuaikan jangkauan siswa, feedback dan koreksi diberikan langsung kepada siswa yang kurang tepat melakukan gerakan keterampilan teknik dasar smash bolavoli hal ini dilakukan dengan berulangulang. Setelah itu siswa diajak mencermati tugas ajar yang sudah dilakukan, dengan memberikan kesempatan kepada siswa untuk bertanya baru kemudian dilakukan pendinginan dan berdoa. Minggu berikutnya dilakukan perlakuan yang sama kemudian dilakukan penilaian pada siswa menggunakan rubrik penilaian keterampilan smash bolavoli.

Diperoleh bahwa siswa yang sudah melakukan teknik dasar smash dengan baik dan benar pada gerakan teknik dasar smash. Seperti tampak pada tabel dibawah ini.

Tabel.1 keterampilan teknik dasar smash bolavoli pada siklus I

\begin{tabular}{llc}
\hline \multicolumn{1}{c}{ No. } & \multicolumn{1}{c}{ Unsur gerak } & Siswa \\
\hline 1. & Sikap permulaan & 16 \\
2. & Sikap awalan & 15 \\
3. & $\begin{array}{l}\text { Sikap perkenaan } \\
\text { dengan bola }\end{array}$ & 19 \\
4. & $\begin{array}{l}\text { Sikap akhir saat } \\
\text { mendarat }\end{array}$ & 17 \\
\hline
\end{tabular}

Dari tabel di atas dapat dijelaskan bahwa dari empat unsur gerak diperoleh jumlah siswa yang sudah melakukan teknik dasar smash bolavoli dengan baik dan benar sikap permulaan 16 siswa, sikap awalan 15 siswa, sikap perkenaan dengan bola 19 siswa dan sikap mendarat 17 siswa.
Siklus ke dua pemberian perlakuan yaitu dengan siswa dibariskan dibagi menjadi 3 baris, Kemudian siswa diiberikan penjelasan tentang bentuk pembelajaran yang akan dilakukan pada siklus kedua, yaitu posisi awalan, tolakan, melayang dan mendarat untuk pelaksanaan rangkaian meningkatkan hasil belajar teknik smash dengan penerapan bola gantung. Sebelumnya siswa diberikan contoh cara melakukan pembelajaran teknik dasar smash yang benar, mulai dari sikap awalan, tolakan, melayang dan mendarat dengan menggunakan media bola gantung. Setiap siswa melakukan rangkaian teknikdasar smash berulang sampai benar-benar menguasai gerakan ini secara berurutan dengan bola gantung. Dalam proses pembelajaran jika ada siswa yang salah melakukan teknidasar smash, dan gerakan lanjutannya dilakukan perbaikan berulangulang sampai bisa melakukan cara menangkap bola mendatar. Sehingga diperoleh hasil pengamatan teknik dasar smash bolavoli siswa yang sudah melakukan teknik dasar smash dengan baik dan benar sebagai berikut.

Tabel.2 Keterampilan teknik dasar smash bolavoli pada siklus II

\begin{tabular}{llc}
\hline No. & \multicolumn{1}{c}{ Unsur gerak } & Siswa \\
\hline 1. & Sikap permulaan & 25 \\
2. & Sikap awalan & 27 \\
3. & $\begin{array}{l}\text { Sikap perkenaan } \\
\text { dengan bola }\end{array}$ & 29 \\
4. & $\begin{array}{l}\text { Sikap akhir saat } \\
\text { mendarat }\end{array}$ & 29 \\
\hline
\end{tabular}

Dari tabel di atas dapat dijelaskan bahwa dari empat unsur gerak diperoleh jumlah siswa yang sudah melakukan teknik dasar smash 


\begin{tabular}{|c|c|c|}
\hline & Journal STAND: Sports and Development \\
unipa Sumalaya & http:/jurnal.unipasby.ac.id/index.php/stand/about/submissions \\
jurnal.stand@unipasby.ac.id
\end{tabular}

bolavoli dengan baik dan benar sikap permulaan 25 siswa, sikap awalan 27 siswa, sikap perkenaan dengan bola 29 siswa dan sikap mendarat 29 siswa.

Berdasarkan penelitian di atas menunjukan bahwa dengan media bola gantung dapat terlihat peningkatan keterampilan teknik dasar smash bolavoli pada siswa kelas $7 \mathrm{H}$ di MTsN 2 Sumenep.

Belajar merupakan proses perbuatan yang dilakukan dengan sengaja, yang kemudian misenimbulkan perubahan, yang akan menjadi suatu proses kegiatan yang mengakibatkan suatu perubahan tingkah laku. sebagai guru dalam melaksanakan kegiatan pembelajaran memiliki kreativitas yang tinggi dalam memanfaatkan dan mengembangkan media serta memilih metode yang tepat untuk siswa.

Sesuai dengan yang dikatakan Erfian (2013: 24) penggunaan media bola gantung dalam penelitian ini adalah bola yang digantung dengan seutas tali yang diikat pada ujung tiang yang berporos pada pengikat tali, dengan menggunakan bolavoli pada ketinggian sesuai dengan jangkauan pemain. Latihan memukul bola gantung secara mekanik mampu mengembangkan kecepatan dan ketepatan memukul bola. Dengan awalan langkah serta ketepatan memukul bola yang dilakukan secara berulang-ulang dapat melatihrespon memukul bola yang pas dan dapat melatih respon memukul bola yang pas dan dapat melatih agar mencapai raihkan bola yang tinggi serta lompatan yang tinggi pula.

\section{KESIMPULAN}

Berdasarkan penelitian yang telah dilaksanakan, maka dapat disimpulkan bahwa telah terjadi peningkatan keterampilan teknik dasar smash bolavoli pada siswa kelas $7 \mathrm{H}$ di MTsN 2 Sumenep melalui penggunaan media bola gantung yang dilakukan dengan dua siklus.

\section{REFERENSI}

Redaksi Tim. 2008. Buku Pintar Bola Voli. Jakarta: Perpustakaan Nasional RI: Katalog Dalam Terbitan (KDT).

Listina Ria. 2012. Mengenal Olahraga Bola Voli. Jakarta: PT Balai Pustaka (Persero).

Kurniawan, Feri. 2012. Buku Pintar Pengetahuan Olahraga. Jakarta: Laskar Aksara.

Fathurrohman Muhammad. 2017. Belajar dan Pembelajaran Modern: Konsep Dasar, Inovasi dan Teori pembelajaran. Yogyakarta Garudhawaca.

Suardi Moh. 2018. Belajar dan Pembelajaran. Yogyakarta: Deepublish.

Erfian Dedy, Setyawan. 2013. Skripsi: Pengaruh Latihan Memukul Bola Gantung TerhadapKetepatan Smash Peserta Ekstrakulikuler Bolavoli di SMK Tunas Cawan Klaten. Yogyakarta: Universitas Negeri Yogyakarta.

Zuhermandi, Saputra Rachmat, Wakidi. 2015. Penerapan Media Bola Gantung Untuk Meningkatkan Aktivitas Smash Dalam Permainan Bola Voli pada Siswa Kelas $X$ B SMA NEGERI 1 Nanga Pinoh. Jurnal Pendidikan Jasmani Kesehatan dan Rekreasi. 